\title{
Pembangunan Sistem Pengukuran Muka Air Otomatis (Automatic Water Level Recorder) Berbasis Gelombang Akustik Untuk Pengamatan Pasang Surut Laut
}

\author{
AGUNG PANDI NUGROHO, NIRMAWANA SIMARMATA, IRDAM ADIL
}

\author{
Pusat Penelitian Penginderaan Jauh dan Informasi Geospasial (P3JIG) \\ Teknik Geomatika - Institut Teknologi Sumatera, Lampung \\ Email : agung@gt.itera.ac.id
}

\begin{abstract}
ABSTRAK
Pasang surut adalah fenomena naik turunnya muka dir. Pasut dapat diukur dengan berbagai macam metode, baik manual maupu otomatis. Pengukuran otomatis dengan menggunakan alat pengukur pasut, khususnya untuk pengukuran jangka panjang dinilai relatif lebih berbiaya rendah dibandingkan dengan pengukuran manual, akan tetapi alat pengukur pasut otomatis hampir semuanya memiliki harga yang relatif mahal sehingga diperlukan peralatan yang lebih terjangkau dan andal. Pengembangan sistem automatic water level recorder (AWLR) berbasis gelombang akustik dilakukan dengan membangun dan merancang sistem perangkat lunak maupun perangkat keras alat dengan berbasiskan perangkat open source Arduino. Alat yang dihasilkan dapat mengukur dengan baik di skala laboratorium maupun lapangan. Pengukuran skala lapangan menunjukkan RMSE $36,6 \mathrm{~cm}$ di daerah terpencil dan RMSE $11 \mathrm{~cm}$ untuk daerah yang memungkinkan alat dipasang dengan stabil.
\end{abstract}

Kata Kunci : AWLR, pengukur pasut otomatis, skala lapangan, skala laboratorium.

\begin{abstract}
Tides were phenomenon of rising water levels. Tides could be measured by various methods, manual or automatic way. Measurements using automatic tide gauges, especially for long-term measurements, usually needed lower cost compared to manual ones, but in facts automatic tide gauges were relatively more expensive prices, so it was worthy to develop the reliable equipment with lower cost. This automatic water level recorder (AWLR) system using acoustic waves was developed by building and designing a software and hardware system based on an open source device named Arduino. The builded equipment had could reached well level in scales, laboratory or field scales. Field scale measurements showed that RMSE in outlying areas reached 36.6 centimeters and could be better for areas where tide gauges could be installed stably (11 centimeters).
\end{abstract}

Keywords: AWLR, automatic tide gauges, field scale, laboratory scale 


\section{PENDAHULUAN}

Pada dasarnya pasang surut (pasut) air laut adalah gelombang yang memiliki periode yang sangat panjang yang bergerak melalui lautan. Hal tersebut utamanya disebabkan adanya gaya tarik menarik dari bulan dan matahari (Ross, 1995). Secara fisik fenomena pasut dapat dilihat dengan naik-turunnya muka air laut sesaat secara periodik (Poerbandono dan Djunarsyah, 2005). Pengamatan pasut bermanfaat untuk berbagai macam bidang, mulai dari bidang ilmu pengetahuan, transportasi, pengembangan sumber daya alam, hingga bidang kebencanaan. Menurut DEC (2014) pengetahuan akan pasang surut air laut bermanfaat untuk melakukan mitigasi terkait banjir maupun abrasi pantai dan dapat memberikan informasi terkait hal yang harus dilakukan untuk melakukan mitigasi bencana di pesisir, salah satunya adalah penanaman penahan gelombang alami seperti pohon bakau.

Pasut dapat diukur dengan menggunakan metode manual maupun otomatis. Pengamatan manual memiliki mekanisme yang cukup sederhana, yaitu dengan memasang palem yang memiliki ukuran, lalu secara berkala dilihat dan dicatat angkanya selama waktu tertentu dengan interval waktu yang telah ditentukan. Metode lainnya adalah dengan menggunakan metode otomatis, yaitu menggunakan alat yang biasa dinamakan tide gauge (data logger). Tide gauge dapat dibagi lagi ke beberapa metode, yaitu metode pengukuran menggunakan pelampung (mekanik) lalu tekanan, akustik, dan gelombang elektromagnetik (elektronik) (Miguez, 2005). Penelitian ini menggunakan pengamatan pasut menggunakan gelombang ultrasonik, selain karena relatif lebih mudah dibuat, metode ini juga yang memiliki akurasi cukup baik dalam pengamatan pasut (Kurniawan, 2016).

Pengukuran otomatis dengan menggunakan alat pengukur pasut (dapat disebut tide gauge atau automatic water level recorder (AWLR)), khususnya untuk pengukuran jangka panjang (lebih dari 15 hari) dinilai relatif lebih berbiaya rendah dibandingkan dengan pengukuran manual. Hal ini khususnya dapat dilihat dari komponen biaya operasionalnya. Walaupun begitu, alat pengukur pasut otomatis hampir semuanya dibuat oleh negara lain yang memiliki harga relatif yang mahal untuk pembelian dan perawatan sehingga pengukuran pasut masih merupakan barang mewah di negara ini. Dengan dikembangkannya sistem ini diharapkan pengukuran pasut untuk penelitian maupun keperluan praktis khususnya di daerah yang terpencil (belum ada stasiun pasut) dapat dilakukan dengan harga yang lebih terjangkau dengan hasil yang baik.

\section{METODOLOGI}

Secara garis besar penelitian ini dilakukan melalui beberapa tahap, yaitu: tinjauan pustaka, perancangan dan pembuatan perangkat, pembuatan algoritma perangkat lunak, pengujian laboratorium, lalu pengujian lapangan. Metode penelitian yang digunakan pada penelitian pembangunan sistem automatic water level recorder berbasis gelombang akustik untuk pengamatan pasang surut laut dapat dilihat pada Gambar 1.

Konsep utama dari penentuan tinggi muka air adalah pengukuran jarak menggunakan gelombang ultrasonik. Oleh karena itu, tahapan pertama dalam penelitian ini adalah mencari literatur yang berhubungan dengan sistem pengukuran jarak dengan perangkat keras dan lunak dari pengendali mikro berbasis open source Arduino Uno. Arduino adalah platform perangkat lunak maupun perangkat keras yang berbasis open source. Platform tersebut memiliki keutamaan, antara lain adalah: harganya yang relatif murah, dapat digunakan pada sistem operasi manapun, dan penggunaannya relatif mudah digunakan sehingga dapat dipakai oleh orang yang awam sekalipun (Arduino, 2017). 


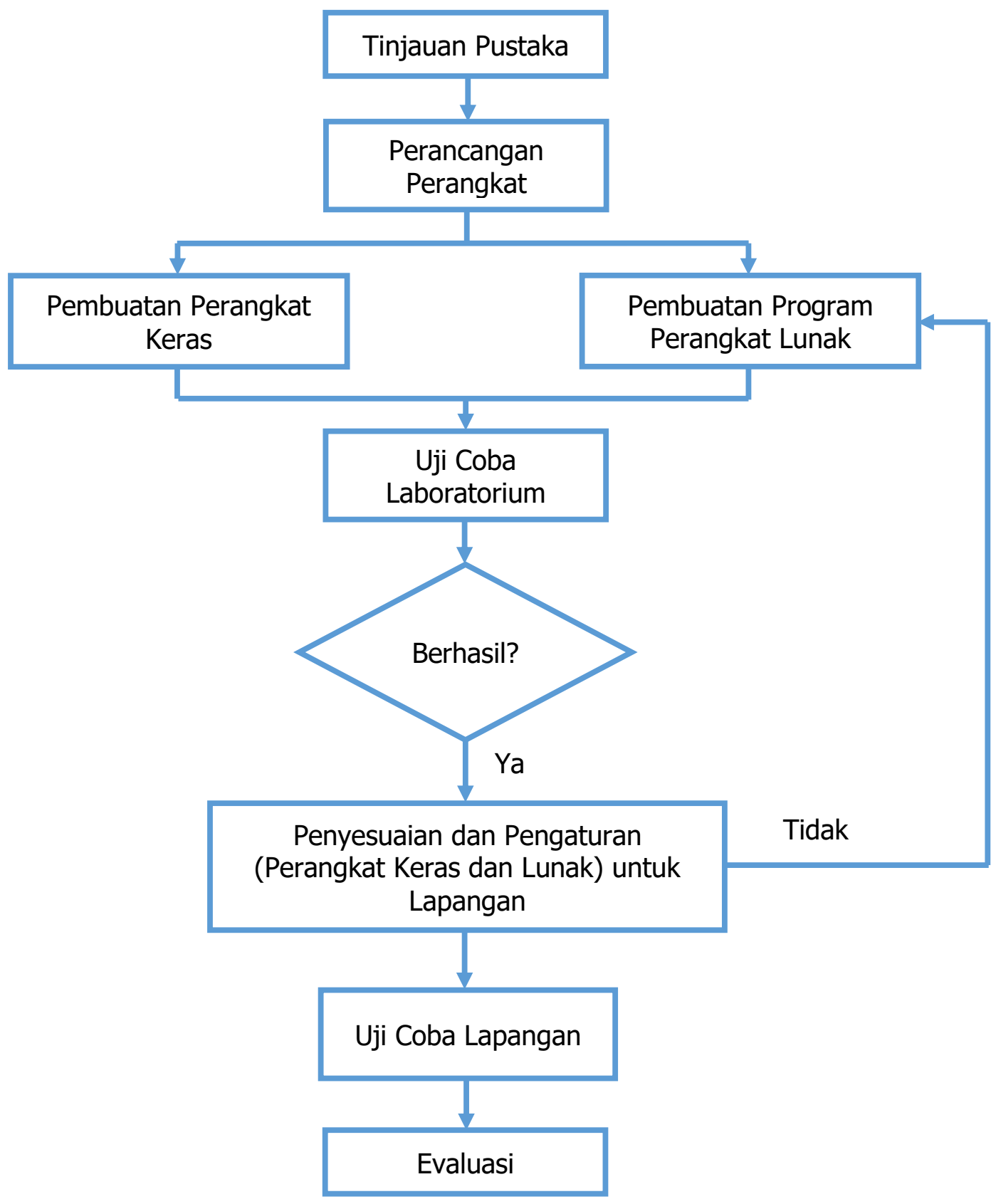

Gambar 1. Skema metode penelitian

Tahap lanjutannya adalah perancangan sistem. Pada tahap ini dilakukan perancangan sistem pengukuran berupa perangkat lunak dan keras. Perangkat lunak yang digunakan adalah perangkat lunak Arduino yang berfungsi untuk mengatur proses kerja dari perangkat keras yang akan dibuat. Untuk bagian perangkat keras utamanya dibuat digunakan pengendali mikro Arduino Uno dan terdiri dari komponen lainnya, seperti modul sensor ultrasonik, papan PCB, layar LCD, dan kabel. Modul sensor ultrasonik yang dipakai adalah sensor yang dimaksudkan untuk mengukur jarak dengan menggunakan Persamaan 1.

$$
S=\frac{1}{2} \cdot \Delta \mathrm{t} \cdot \mathrm{v}
$$

di mana $S=$ jarak, $\Delta$ t = waktu tempuh gelombang, $v=$ kecepatan gelombang (menggunakan besaran 340 meter/detik). 
Perangkat lunak dan keras yang telah selesai lalu diujicobakan di laboratorium. Uji coba ini dilakukan untuk memastikan semua perangkat dan sensor berfungsi sesuai dengan yang diinginkan. Uji coba dilakukan dengan melakukan pengukuran jarak di laboratorium dan di perairan tenang (kolam atau embung). Setelah semua terpasang dan bekerja dengan baik, uji coba selanjutnya dilakukan di lapangan (laut). Evaluasi dilakukan pada tahap akhir untuk menentukan kemampuan alat untuk mengukur pasut di laut untuk diketahui kekurangan dan kelebihan alat sehingga dapat diperbaiki dan dibuat rekomendasi untuk perbaikan ke depannya.

\section{HASIL DAN PEMBAHASAN}

\subsection{Perancangan dan Pembuatan Alat}

Pada tahap ini dilakukan perancangan alat dan sistem pengukuran pasut. Pembuatan perangkat keras ( hardware) diawali dengan pencarian komponen untuk dirancang dan dirakit. Komponen yang telah dikumpulkan disusun menjadi satu dan dirangkai dengan seksama. Lalu setelah semua rangkaian sudah dirangkai dengan baik, kesemua rangkaian disambungkan dengan kabel listrik, kabel data lalu dimasukkan dalam suatu case (wadah) tertutup yang tebuat dari plastik dan ditutup semua rongganya menggunakan lem dan gemuk. Komponen, struktur, dan hasil rangkaian dapat dilihat pada Gambar 2.
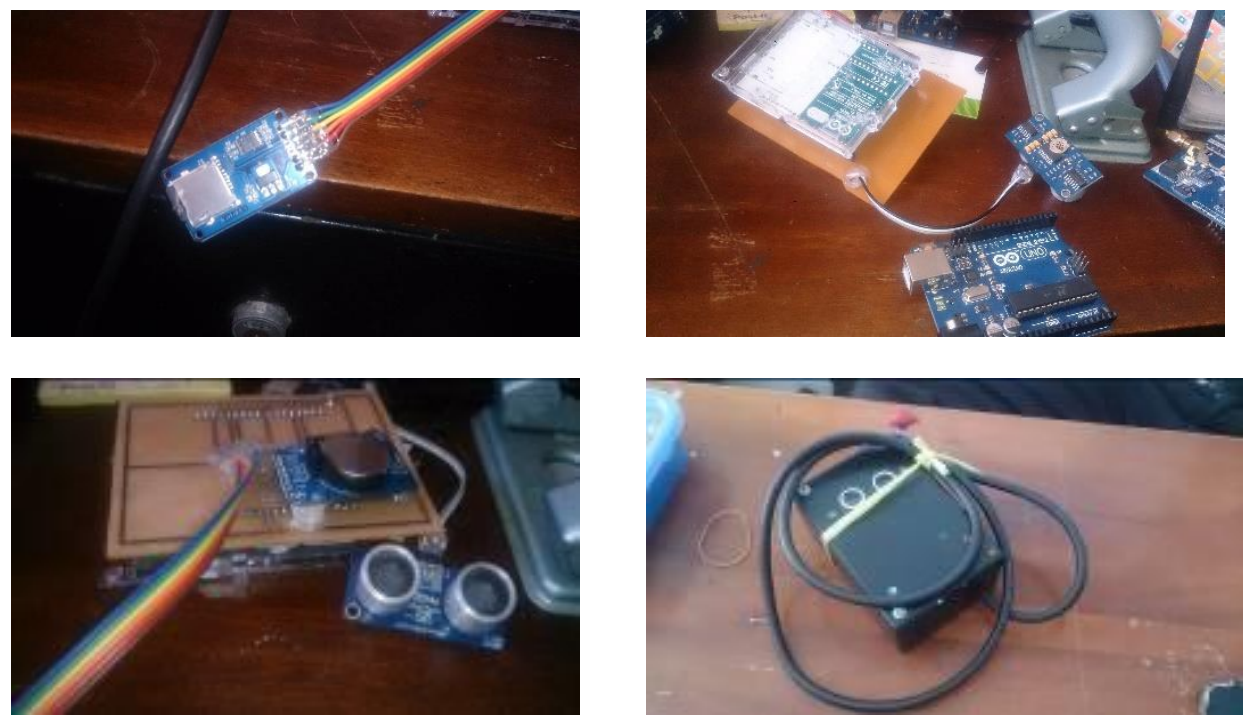

Gambar 2. Komponen, Pemasangan Alat, dan Alat yang Sudah Dirangkai

Secara umum skema pengukuran pada alat AWLR ini sesuai dengan yang sudah dijelaskan sebelumnya, yaitu menggunakan rumus pengukuran jarak gelombang suara (lihat Persamaan 1) sehingga untuk mendapatkan data yang diinginkan diperlukan juga komponen lain selain dari sensor suara, yaitu: jam, baterai, dan media penyimpanan data. Skema kerja perangkat keras AWLR dapat dilihat pada Gambar 3.

Pada tahapan selanjutnya dilakukan pembuatan sketch. Pemrograman untuk Arduino dengan menggunakan bahasa $\mathrm{C}+$ biasa disebut dengan sebutan skecth. Selain pengaturan dalam sebagai pembacaan data sensor, sketch ini berfungsi juga sebagai pengolah data sensor dan penampil indikator (Al Hakim, 2017). Datap dikatakan bahwa sketch ini adalah pembuatan otak dari sistem yang sedang dibangun. Diagram atau algoritma kerja alat dapat dilihat pada skema pada Gambar 4. 

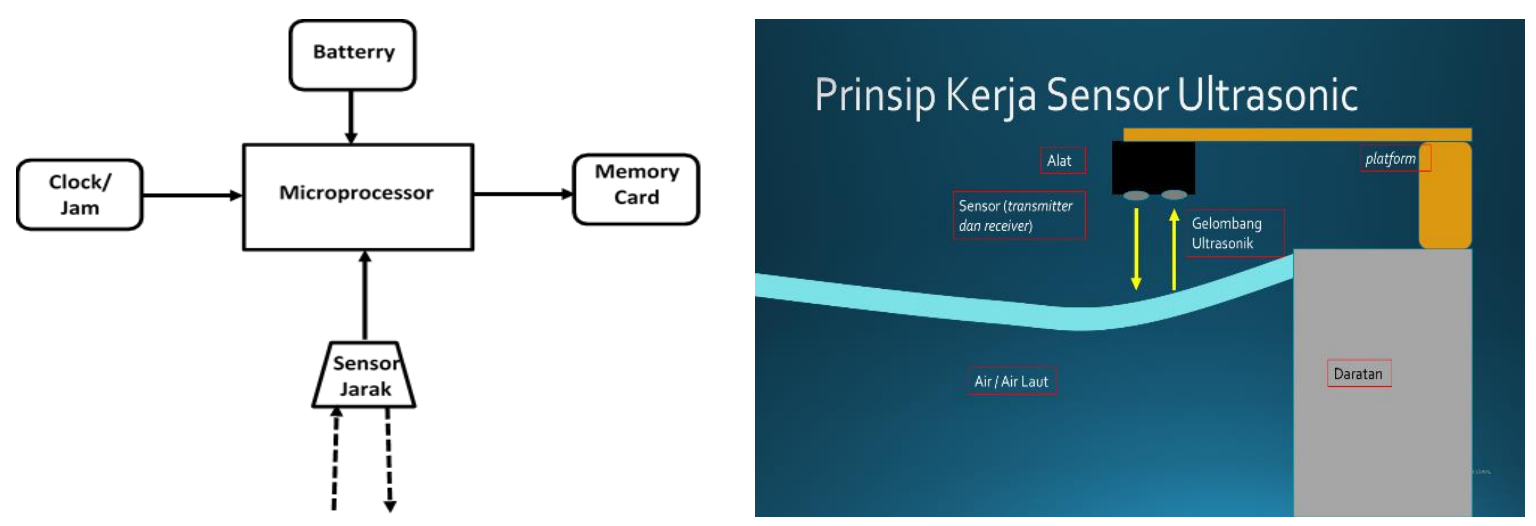

Gambar 3. Skema Kerja Perangkat Keras

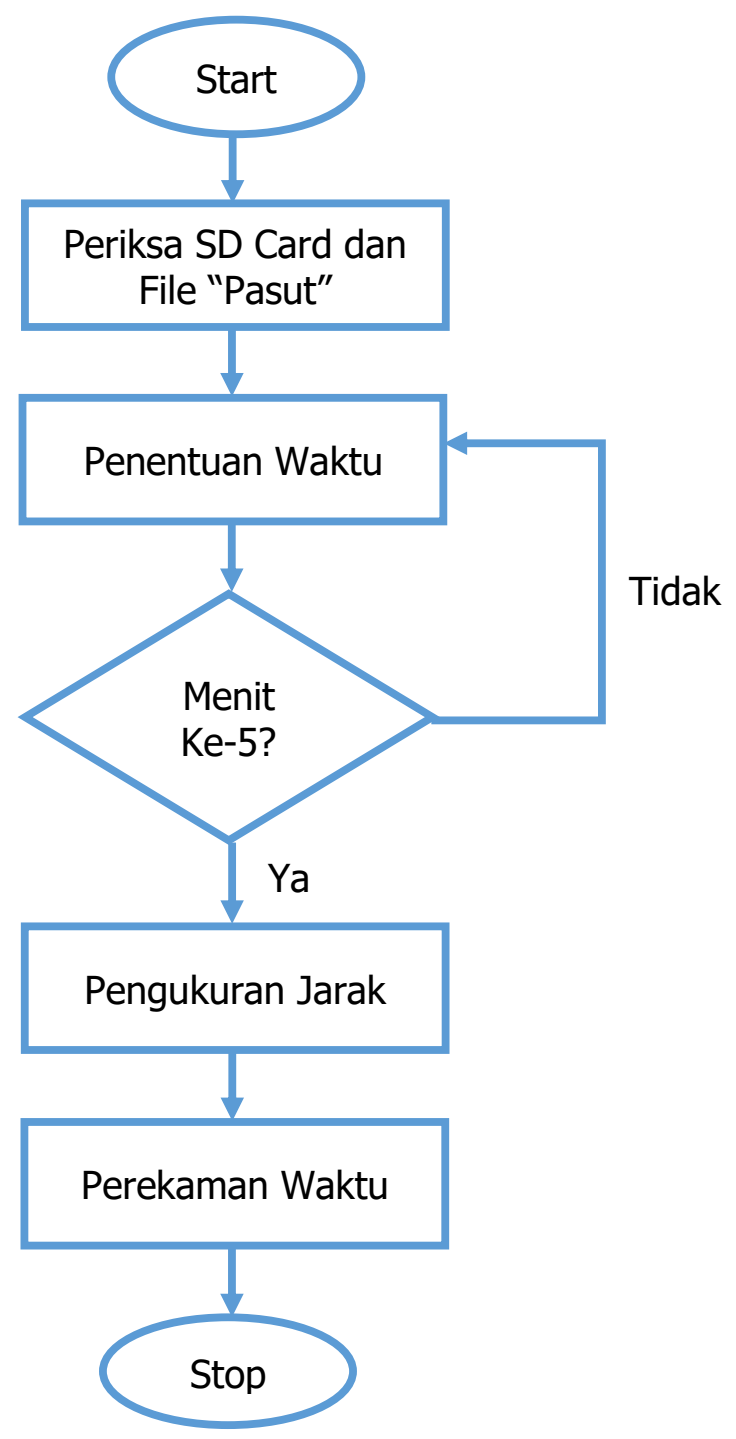

Gambar 4. Skema Kerja dan Algoritma Alat 


\subsection{Pengukuran dan Uji Laboratorium}

Setelah semua alat terpasang dengan baik dan sistemnya sudah ter-instal/ maka dilakukan tahap selanjutnya, yaitu uji coba sistem yang pertama. Ujicoba sistem dilakukan di laboratorium dan embung (danau buatan). Pada percobaan ini alat dinyalakan, dipasang, dan dilakukan pengambilan data selama kurang lebih dua hari di luar ruangan (Gambar 5).
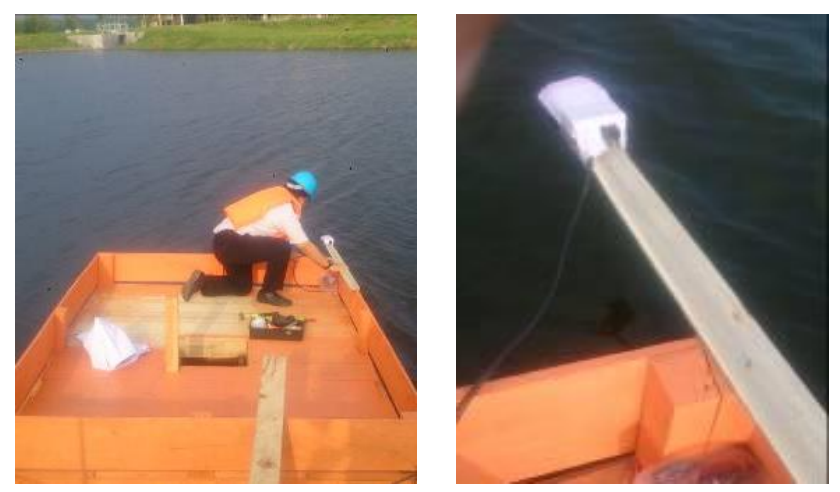

\section{Gambar 5. Percobaan Alat Di Embung (Danau Buatan)}

Setelah alat dipasang lalu dilakukan pengecekan data. Data diunduh dan dilakukan proses plot data. Hasil data yang sudah diplot dapat dilihat pada Gambar 6. Dari hasil tersebut secara garis besar pengukuran berjalan dengan lancar (data yang rata menunjukkan muka air yang tenang dan datar), hanya saja terlihat ada beberapa kelompok data yang berada di luar kewajaran (outlier). Hal tersebut dikarenakan terjadinya hujan yang cukup deras pada saat pengukuran yang menyebabkan bacaan alat terganggu. Air hujan selain menimbulkan riak juga menghalangi jalur gelombang suara menuju permukaan air yang diinginkan.

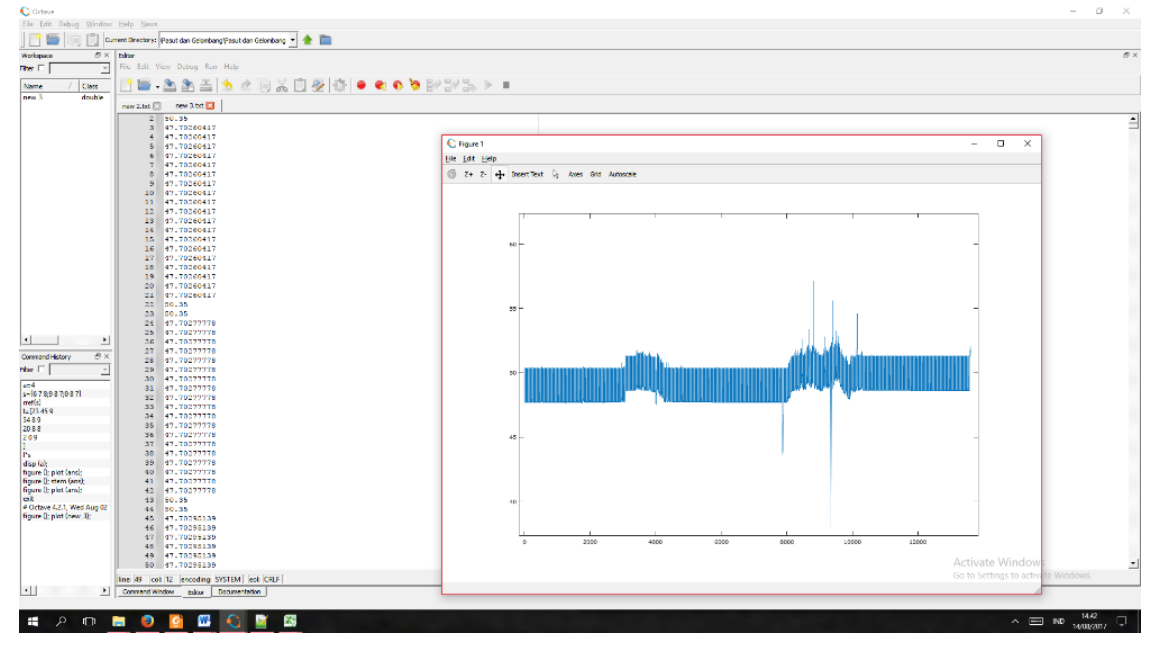

Gambar 6. Data Hasil Percobaan Pengukuran di Embung

\subsection{Uji Lapangan}

Uji coba di lapangan dimaksudkan untuk menguji fungsionalitas alat, seperti kemampuan pengambilan data, ketangguhan alat, dan untuk mencari permasalahan-permasalahan yang mungkin akan timbul pada saat pengukuran di lapangan. Hal tersebut penting untuk diketahui karena pemasangan alat dan pengukuran nyata dari pasut merupakan pengukuran yang berlangsung lama, tempatnya tidak menentu (mulai di pelabuhan di daerah perkotaan hingga tempat terpencil yang mungkin tidak berpenghuni) dan pengukuran yang harus dapat terus 
dilakukan walaupun cuaca ekstrem seperti badai dan hujan deras terjadi. Hal tersebut belum ditambah kondisi laut yang tidak bersahabat dengan alat elektronik.

Uji coba lapangan dilakukan di dua tempat, yang pertama di pantai yang berada di Pulau Maitam, di wilayah administrasi Kabupaten Pesawaran. Pulau adalah pulau objek wisata yang tidak berpenghuni, di pulau ini juga tidak terdapat pelabuhan karena merupakan pulau yang dimaksudkan untuk membantu pelayaran di sekitar Teluk Lampung sehingga memiliki instalasi mercusuar. Ketidaktersediaannya pelabuhan maupun bangunan yang menjorok ke laut ditambah keadaaan pantai yang berbatu curam membuat instalasi alat yang stabil untuk pengukuran yang baik agak sulit untuk dilakukan. Instalasi pengukuran dapat dilihat pada Gambar 7 a. Pada uji coba lapangan ini data tidak didapatkan karena kerusakan sensor (karat). Setelah kejadian tersebut dilakukan revisi model alat dengan menggunakan sensor baru yang lebih kuat dan akurat (Gambar 7 b).

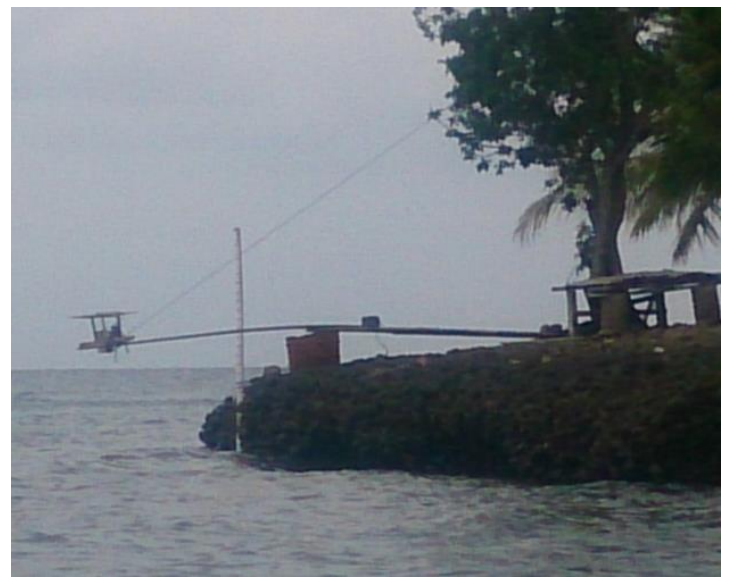

(a)

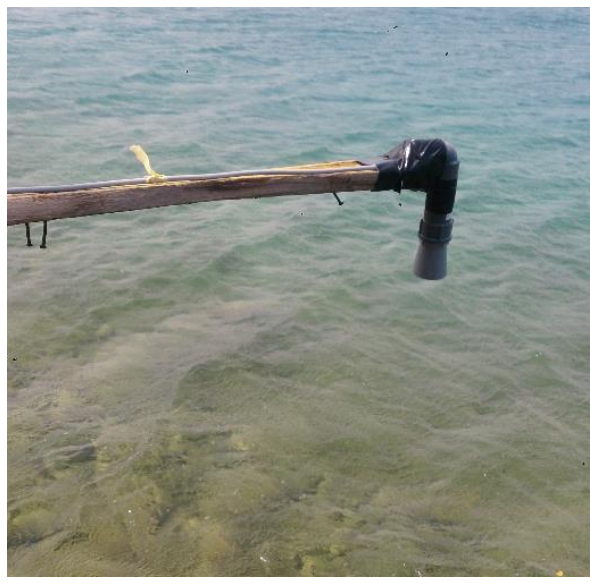

(b)

\section{Gambar 7. (a) Instalasi alat AWLR Pertama di Pulai Maitam, (b) Penggunaan Sensor Baru}

Hasil dari pengukuran mendapatkan data pasut selama kurang dua hari. Hasil tersebut pada awalnya akan dibandingkan dengan pengamatan palem, akan tetapi saat pengukuran palem dengan perekaman data oleh alat tidak sinkron waktunya sehingga tidak dapat dilakukan perbandingan. Ketidaksinkronan waktu tersebut terjadi karena kegagalan alat untuk merekam pada saat pembacaan palem dilakukan. Kegagalan tersebut baru diketahui setelah memory card dilepas dan data diunduh serta dilihat pada komputer. Karena tidak memungkinkan dibandingkan dengan bacaan palem mak untuk membandingkan data pasut digunakanlah model prediksi pasut Badan Informasi Geospasial yang diakses di laman tides.big.go.id. Perbandingan tersebut menghasilkan grafik yang dapat dilihat pada Gambar 8. Dari pengukuran tersebut didapat Root Mean Square Error (RMSE) amplitudo sebesar 36,6 cm.

Uji kedua dilakukan di pelabuhan yang terdapat di Pulau Pramuka, Kepulauan Seribu, Jakarta. Di pulau yang berpenghuni cukup padat ini terdapat pelabuhan dan bangunan yang berada di bibir pantai sehingga instalasi alat lebih mudah untuk dilakukan. Uji dilakukan selama 3 hari dan dilakukan bersamaan dengan pengukuran menggunakan alat lain yang menggunakan metode pengukuran tekanan. Diperoleh hasil seperti dapat dilihat pada Gambar 9. Pengukuran tersebut menghasilkan RMSE sebesar $11,09 \mathrm{~cm}$. 


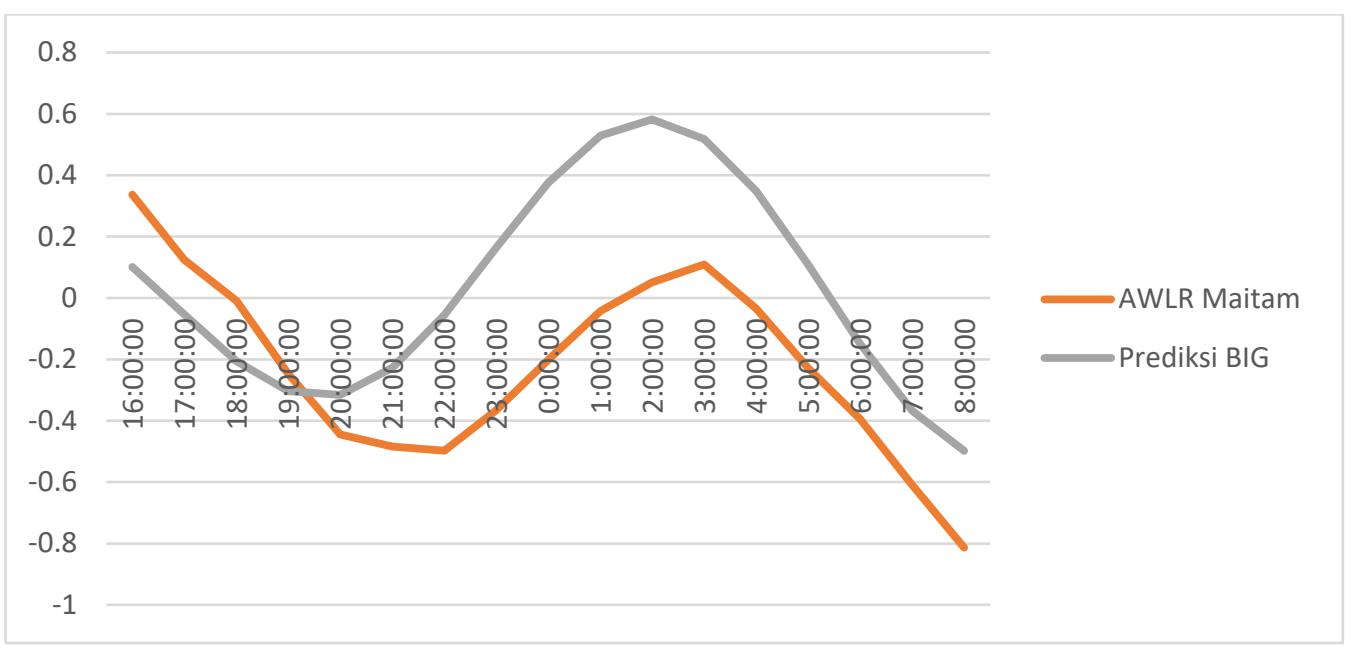

Gambar 8. Hasil Perbandingan Pengukuran di Pulau Maitam

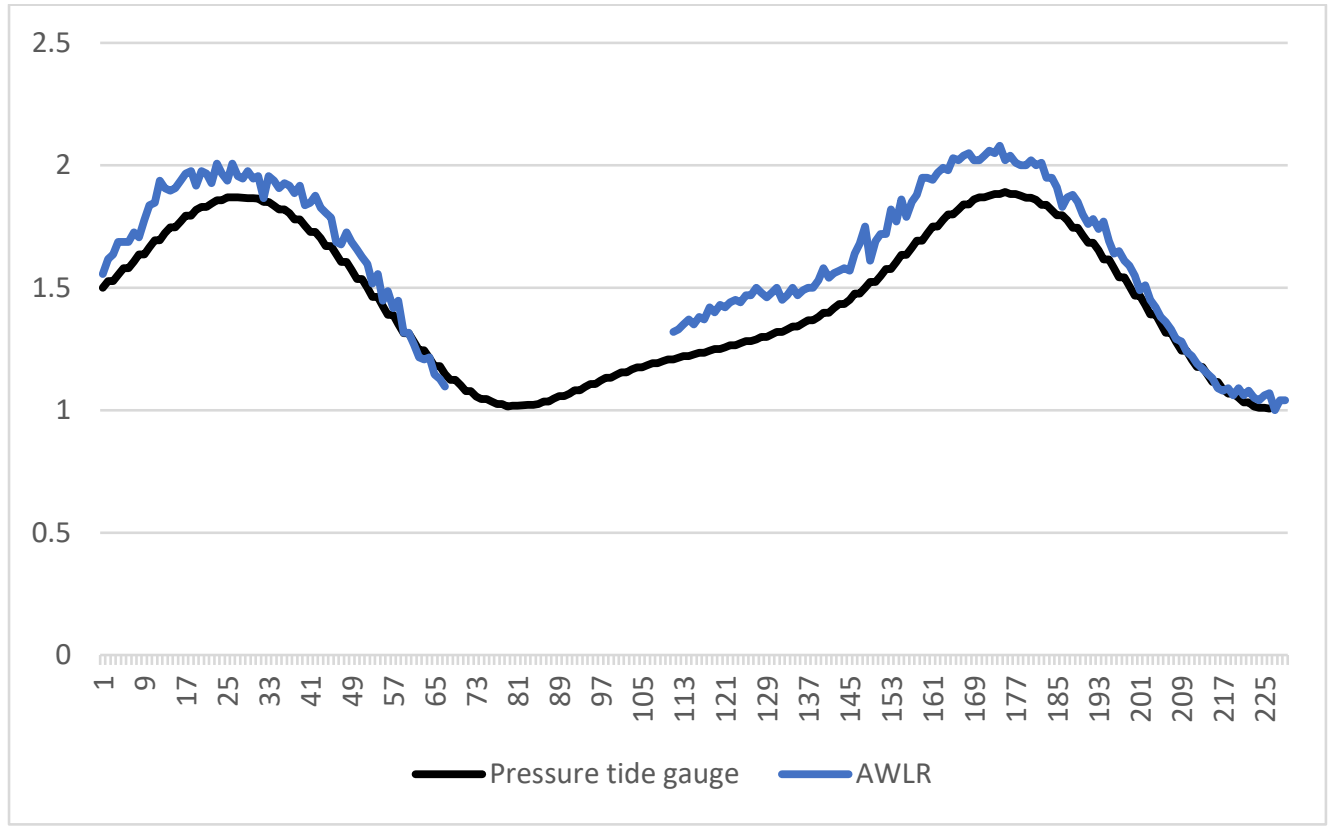

Gambar 9. Hasil Perbandingan Pengukuran di Pulau Pramuka

\section{KESIMPULAN DAN SARAN}

Hasil dari penelitian tentang pembangunan sistem AWLR berbasis gelombang akustik untuk pengamatan pasut adalah berupa sistem yang terdiri dari alat AWLR yang dapat digunakan untuk mengukur pasut. Kesimpulan yang didapatkan adalah bahwa untuk pengukuran pasut di laut alat yang dibuat harus mempertimbangkan ketahanan dalam kondisi yang ekstrem dan udara laut yang cenderung korosif. Perlu juga dilakukan modifikasi agar pemantauan pengambilan data secara realtime dapat dilakukan. Hal ini dilakukan untuk mengantisipasi bila alat tidak merekam data seperti seharusnya sehingga dapat dilakukan tindakan penanggulangan dengan segera. Ketelitian data pengukuran AWLR ini memiliki RMSE 36,6 cm di daerah yang sulit untuk dilakukan instalasi dan RMSE $11 \mathrm{~cm}$ untuk di daerah yang stabil dan mudah dalam instalasi alat. Hal in juga dapat menjadi pertimbangan dan saran ke depannya agar alat dapat tetap stabil walaupun ditempatkan dimana saja. 


\section{UCAPAN TERIMA KASIH}

Dalam penyelesaian penelitian pembangunan sistem automatic water level recorder berbasis gelombang akustik untuk pengamatan pasang surut laut ini terima kasih yang sebesarbesarnya disampaikan kepada Lembaga Peneltian, Pengabdian Kepada Masyarakat dan Penjaminan Mutu (LP3) Institut Teknologi Sumatera (ITERA) atas bantuan dana melalui program dana hibah mandiri. Semoga penelitian ini bermanfaat.

\section{DAFTAR PUSTAKA}

Al Hakim, Y. (2017). Pengembangan Automatic Water Level Recorder (AWLR) untuk Flood Early Warning System (FEWS), The 5th URECOL Proceeding, UAD Yogyakarta.

Arduino. (2017). What is Arduino? Dipetik 2017 dari https://www.arduino.cc/en/Guide/Introduction.

DEC (Departemen of environmental conservation). (2014). Coastal Green Infratructure Research Plan for New Yory City. Arcadis, New York

Kurniawan, D., Yuwono, dan N. Faizal. (2016). Pengujian Ketelitian Hasil Pengamatan Pasang Surut dengan Sensor Ultrasonik (Studi Kasus: Desa Ujung Alang, Kampung Laut, Cilacap). Jurnal Teknik ITS, ITS, Surabaya.

Miguez, B.M.,; B. P., Gomez and E.A. Fanjul. (2005). The ESEAS-RI Sea Level Test Station:Reliability and Accuracy of Different Tide Gauges. International Hydrographic Review, UNB, Canada.

Poerbandono dan Djunarsyah, E. (2005). Survei Hidrografi. Refika Aditama, Bandung

Ross, D.A. (1995). What are Tides?. Dipetik 2017 dari situs: https://oceanservice.noaa.gov. 